one million patients would protect 50000 people from death or disability. Large scale randomised controlled trials have the potential to make an important contribution to the prevention of death and disability from this growing epidemic. ${ }^{16} 17$

We thank Simona Fiore, Olivier Duperrex, and Leah Li for translating the Italian, Spanish, French and Chinese trial reports; and Iain Chalmers, Doug Altman, and Richard Peto for their comments on the manuscript.

Funding: The Cochrane Injuries Group is funded by the NHS Executive.

Competing interests: None declared.

Contributors: KD extracted the data and commented on the paper. FB extracted the data, created the trial database, analysed the data, and commented on the paper. RW conducted the searches, obtained the trial reports, translated the German papers, and commented on the paper. PE conducted the statistical analyses, prepared the figures, and commented on the paper IR proposed the study, coordinated its conduct, and wrote the paper. IR is guarantor.

1 Murray CJL, Lopez AD. Global health statistics: a compendium of incidence, prevalence and mortality estimates for over 200 conditions. Boston: Harvard University Press, 1996.

2 World Bank. Global road safety partnership. Washington, DC: World Bank, 1999.

3 Peto R, Collins R, Gray R. Large-scale randomised evidence: large simple trials and overviews of trials. J Clin Epidemiol 1995;48:23-40.

4 Schulz KF, Chalmers I, Hayes RJ, Altman DG. Empirical evidence of bias. Dimensions of methodological quality associated with estimates of treatment effects in controlled trials. JAMA 1995;273:408-12.
5 Teasdale G. The treatment of head trauma: implications for the future. J Neurotrauma 1991;8(suppl 1):53-60.

6 Royal College of Surgeons of England. Report of the working party on the management of patients with head injury. London: Royal College of Surgeons, 1999.

7 Roberts I, Schierhout G, Alderson P. Absence of evidence for the effectiveness of five interventions routinely used in the intensive care management of severe head injury: a systematic review. J Neurol Neurosurg Psychiatry 1998;65:729-33

8 CAST (Chinese Acute Stroke Trial) Collaborative Group. CAST randomised placebo-controlled trial of early aspirin use in 20000 patients with acute ischaemic stroke. Lancet 1997;349:1641-9.

9 ISIS-2 (Second International Study of Infarct Survival) Collaborative Group. Randomised trial of intravenous streptokinase, oral aspirin, both or neither among 17187 cases of suspected acute myocardial infarction. Lancet 1988;ii:349-60.

10 International Stroke Trial Collaborative Group. International stroke trial (IST): a randomised trial of aspirin, subcutaneous heparin, both, or neither among 19435 patients with acute ischaemic stroke. Lance 1997;349:1569-81.

11 Kunz R, Oxman AD. The unpredictability paradox: review of empirical comparisons of randomised and non-randomised clinical trials. $B M J$ 1998:317:1185-90.

12 Liberati A, Himel HN, Chalmers TC. A quality assessment of randomised controlled trials of primary treatment of breast cancer. J Clin Oncol $1986 ; 4: 942-51$

13 Ad Hoc Committee on Health Research Relating to Future Intervention Options. Investing in health research and development. Geneva: World Health Organization, 1996.

14 Smith R. Informed consent: the intricacies. BMJ 1997;314:1059-60.

15 Department of Health and Human Services, Food and Drug Administration. Protection of human subjects: informed consent. Fed Reg 1995;60:49086-103

16 Yates D, Farrell B, Teasdale G, Sandercock P, Roberts I. Corticosteroids in head injury-the CRASH trial. J Accid Emerg Med 1999;16:83-90.

17 www.crash.ucl.ac.uk (accessed 10 Mar 2000).

(Accepted 3 February 2000)

\title{
Suicidal ideation among outpatients at general neurology clinics: prospective study
}

\author{
Alan J Carson, Steven Best, Charles Warlow, Michael Sharpe
}

Suicide is one of the ten most common causes of death for both men and women in Great Britain. ${ }^{1}$ Psychiatric disorders are the main risk factor, but numerous studies have also identified physical illness as an important contributory factor. ${ }^{12}$ Although it is considered mandatory to enquire about suicidal ideation in psychiatric consultations, this is seldom part of a medical assessment. We aimed to examine suicidal ideation in a consecutive series of patients who had been newly referred to general neurology outpatient clinics. The study was approved by the local research ethics committee.

\section{Participants, methods, and results}

As part of another study, 300 of 312 consecutive new patients at the general neurology outpatient clinics at the Western General Hospital, Edinburgh, were interviewed using the primary care evaluation of mental disorders (PRIME-MD) structured psychiatric interview schedule. ${ }^{4}$ As part of the interview all patients were asked: "In the last two weeks, have you had thoughts that you would be better off dead or of hurting yourself in some way?"

Patients who answered yes were asked to describe the nature of these thoughts. To be classed as experiencing suicidal ideation the patient had to have thought about active plans for committing suicidesuch as buying tablets-nearly every day for the previous two weeks. Whenever a patient reported such ideation the general practitioner was informed.

Diagnoses of anxiety and depressive disorders that were made using the structured interview were also recorded. After the clinical consultation, the neurologists recorded the neurological diagnosis and whether the patient required psychiatric or psychological assessment or treatment.

Before a patient attended the clinic the patient's general practitioner was sent a brief questionnaire. The general practitioners were asked to indicate whether they believed that the patient required psychiatric or psychological assessment or treatment.

At the time of assessment the researchers were blind to the opinions of the neurologists and the general practitioners.

The clinical characteristics of the patients attending the clinics are shown in the table. One in 11 patients (26/300) seen at the general neurology clinics had given serious thought to committing suicide in the past two weeks. Almost all of these patients (23/26) had major depression. It might be assumed that suicidal ideation would be more likely to occur in patients with progressive, debilitating neurological conditions. However, this was not the case. Twelve of the 26 patients who had experienced suicidal ideation had medically unexplained symptoms, and most of the remainder had non-progressive conditions.
Department of Psychiatry, University of Edinburgh, Royal Edinburgh Hospital, Edinburgh EH10 5HF

Alan J Carson lecturer, psychiatry Steven Best medical student

Michael Sharpe senior lecturer, psychological medicine

Department of Clinical

Neuroscience, University of Edinburgh, Western General Hospital, Edinburgh EH4 2XU

Charles Warlow professor, medical neurology

Correspondence to: A J Carson A.Carson@ed.ac.uk

BMJ 2000;320:1311-2 
Clinical characteristics of new patients attending neurology outpatient clinics. Values are numbers (percentages) unless indicated otherwise

\begin{tabular}{|c|c|c|c|}
\hline & $\begin{array}{l}\text { Patients with } \\
\text { suicidal ideation* } \\
(\mathrm{n}=26)\end{array}$ & $\begin{array}{c}\text { Patients without } \\
\text { suicidal ideation } \\
\quad(n=274)\end{array}$ & $\begin{array}{l}\text { Relative risk } \\
(95 \% \mathrm{Cl})\end{array}$ \\
\hline Men & $12(46)$ & $114(42)$ & $1.11(0.71$ to 1.72$)$ \\
\hline Women & $14(54)$ & $160(58)$ & $0.84(0.40$ to 1.76$)$ \\
\hline Age $\leqslant 40$ years & $15(58)$ & $128(47)$ & $1.50(0.71$ to 3.15$)$ \\
\hline Has medically unexplained symptoms & $12(46)$ & $78(28)$ & $1.62(1.03$ to 2.56$)$ \\
\hline Has non-progressive neurological disease $\dagger$ & $12(46)$ & $153(56)$ & $0.83(0.54$ to 1.27$)$ \\
\hline $\begin{array}{l}\text { Has potentially progressive neurological } \\
\text { diseaseł }\end{array}$ & $2(8)$ & $43(16)$ & $0.49(0.13$ to 1.91$)$ \\
\hline Major depressive disorder diagnosed & $23(88)$ & $54(20)$ & 4.49 (3.40 to 5.92$)$ \\
\hline \multicolumn{4}{|l|}{ Identified as needing psychiatric assessment:§ } \\
\hline By general practitioner & $8(31)$ & $43(16)$ & NA \\
\hline By neurologist & $12(46)$ & $40(15)$ & NA \\
\hline Not identified & $11(42)$ & $170(62)$ & NA \\
\hline
\end{tabular}

$\mathrm{NA}=$ not applicable.

${ }^{*}$ Prevalence is $9 \%$ ( $95 \%$ Cl $6 \%$ to $\left.12 \%\right)$.

tIncludes conditions such as epilepsy, headache, migraine, and neuropathy.

Includes conditions such as multiple sclerosis, Parkinson's disease, and brain tumours.

$\S$ Not specifically identified as being suicidal.

\section{Comment}

Our findings do not support the view that suicidal ideation occurring in neurology patients is largely a rational response to progressive physical illness. Instead, the findings underscore the importance of major depressive disorder in influencing the ways that medically ill patients think about their illnesses and themselves.

The prevalence of 9\% (95\% confidence interval 6\% to $12 \%$ ) for significant suicidal ideation described in this study is higher than the $2-3 \%$ described as occurring in primary care and community settings in the United States. ${ }^{5}$ We are unaware of any data that indicate what proportion of those who are medically ill and who report suicidal ideation actually go on to kill themselves. None the less, suicidal ideation of the type considered important in this study is clinically significant: it would be taken seriously during a psychiatric consultation.

It is encouraging that $58 \%$ of those patients with suicidal ideation were identified by either the general practitioner or the neurologist as needing psychiatric or psychological assessment or treatment. However, general practitioners and neurologists did not always identify the same patients. This highlights the importance of assessing the mental state of medically ill patients and the importance of communication of the findings between general practitioners and specialists.

Contributors: AC developed the primary hypothesis, discussed core ideas and study design, contributed to data collection and analysis, and participated in writing of the paper. SB assisted with data collection and analysis and contributed to writing the paper. CW and MS discussed core ideas and the design of the study and contributed to writing the paper. MS is guarantor for the paper.

Funding: This study was supported by the University of Edinburgh.

Competing interests: None declared.

1 Diekstra RFW. The epidemiology of suicide and parasuicide. Acta Psychiatr Scand 1993:371(suppl):9-20.

2 Feinstein A. Multiple sclerosis, depression, and suicide: clinicians should pay more attention to psychopathology. BMJ 1997;315:691-2.

3 Carson AJ, Ringbauer B, MacKenzie L, Warlow C, Sharpe M. Neurological disease, emotional disorder and disability: they are related. A study of 300 consecutive new referrals to neurology outpatient clinics. $J$ Neurol Neurosurg Psychiatry 2000;68:202-6.

4 Spitzer RL, Williams JB, Kroenke K, Linzer M, deGruy FV, Hahn SR, et al. Utility of a new procedure for diagnosing mental disorders in primary care. The PRIME-MD 1000 study. JAMA 1994;272:1749-56.

5 Paykel ES, Myers JK, Lindenthal JJ, Tanner J. Suicidal feelings in the general population. A prevalence study. Br J Psychiatry 1974;124:460-9.

(Accepted 24 February 2000)

\title{
Home collection of urine for culture from infants by three methods: survey of parents' preferences and bacterial contamination rates
}

\author{
Lynster C T Liaw, Deepa M Nayar, Stephen J Pedler, Malcolm G Coulthard
}

Royal Victoria Infirmary, Queen Victoria Road,

Newcastle upon Tyne NE1 4LP

Lynster C T Liaw specialist registrar in paediatric nephrology Malcolm G

Coulthard

consultant paediatric

nephrologist

Deepa M Nayar specialist registrar in microbiology

Stephen J Pedler consultant microbiologist

Correspondence to: M G Coulthard malcolm. coulthard@ncl.ac.uk

BMJ 2000;320:1312-3
Urinary tract infection is common in childhood. Infants are most likely to scar and often have non-specific symptoms. Because of practical difficulties with collecting urine, samples are often not obtained. ${ }^{1}$ Most samples are collected by parents, ${ }^{2}$ yet nobody has sought parents' views on available methods. We assessed contamination rates and parents' opinions of three common methods used at home.

\section{Subject, methods, and results}

Parents of children aged 1 to 18 months volunteered to collect urine at home by pads, bags, and clean catch in a randomised order, on one day. The study had ethics committee approval. Demonstrations and instruction sheets were given. Parents washed their hands before each procedure and the child's perineum before each collection. Pads (Newcastle sterile urine collection packs, Ontex UK, Corby) were placed inside the nappy and checked every 10 minutes until wet (but not soiled), then urine aspirated with a syringe. Bags (Hollister U-Bag, Hollister, Libertyville, IL) were applied and inspected every 10 minutes and removed to decant the urine. For clean catch samples, infants were nursed with a sterile bottle ready. Samples were immediately instilled on to dipslides (Till-U-Test, Dimanco, Bedfordshire) with sterile swabsticks and returned with forms recording parents' collection times, comments, and rankings. Equipment costs were: pads 40 pence for 10 (or 59p for a pack containing syringe, bottle, and two pads); bag 89p; sterile bottle 7p; dipslide and swabstick 59p.

Forty four parents attempted collections (29 boys, median age 4 months, range 1 to 18 months). No samples were obtained from one baby with diarrhoea, and no other child had a urine infection. Bacterial counts were $<10^{4} / \mathrm{ml}$ (typically reported as "insignificant" or "no growth") from $31(70 \%)$ pads, 29 (66\%) bags, and $33(75 \%)$ clean catch collections. Seven samples from pads, eight from bags, and one from clean catch collection had contamination $\left(>10^{4} / \mathrm{ml}\right.$ of one or more 